\title{
BIODIESEL DARI MINYAK NYAMPLUNG TEROZONISASI MELALUI ESTERIFIKASI DAN TRANSESTERIFIKASI DENGAN BANTUAN GELOMBANG ULTRASONIK
}

\author{
BIODIESEL MADE OF OZONISED NYAMPLUNG OIL THROUGH \\ ESTERIFICATION AND TRANSESTERIFICATION USING THE \\ HELP OF ULTRASONIC WAVES
}

\author{
Haryono*, Solihudin, Rukiah, Susi Suryani \\ Departemen Kimia, Fakultas Matematika dan Ilmu Pengetahuan Alam, Universitas Padjadjaran \\ *email: haryono_riyo@yahoo.com
}

Diterima 5 Agustus 2016 disetujui 5 September 2016

\begin{abstract}
Abstrak
Bahan bakar dari minyak bumi merupakan sumber energi paling dominan digunakan dan bersifat tak terbarukan. Hal ini menyebabkan semakin berkurangnya cadangan bahan bakar fosil. Hal tersebut mendorong dikembangkannya bahan bakar alternatif terbarukan seperti biodiesel. Tujuan penelitian ini adalah mensintesis biodiesel dari minyak nyamplung melalui proses esterifikasi dan transesterifikasi dengan bantuan ozonisasi dan gelombang ultrasonik. Ozonisasi dilakukan selama 30 menit, sedangkan reaksi transesterifikasi dibantu dengan gelombang ultrasonik pada variasi frekuensi 28 dan $35 \mathrm{kHz}$ masing-masing selama 30 menit. Hasil penelitian menunjukkan bahwa penggunaan gelombang ultrasonik dengan frekuensi $35 \mathrm{kHz}$ pada reaksi transesterifikasi terhadap minyak nyamplung terozonisasi dari reaksi esterifikasi dihasilkan biodiesel yang relatif sesuai dengan standar biodiesel Indonesia. Biodiesel yang dihasilkan pada kondisi tersebut memiliki bilangan asam $0,70 \mathrm{mgKOH} / \mathrm{g}$ biodiesel, bilangan iodium $50,34 \mathrm{~g} \mathrm{I}_{2} / 100 \mathrm{~g}$, titik nyala $122,4^{\circ} \mathrm{C}$, bilangan cetana 102,5 , densitas $0,9088 \mathrm{~g} / \mathrm{cm}^{3}$, dan viskositas $9,5 \mathrm{cSt}$. Yield biodiesel yang diperoleh pada kondisi terbaik adalah sebesar $77,0 \%$.
\end{abstract}

Kata Kunci: biodiesel, minyak nyamplung, ozonisasi, transesterifikasi, ultrasonik.

\begin{abstract}
Fuel from petroleum is the most dominant source of energy used and is non-renewable. This causes the reduction in fossil fuel reserves. It encourages the development of alternative renewable fuels such as biodiesel. The purpose of this study was to synthesize biodiesel from Calophyllum inophyllum oil through esterification and transesterification process with the help of ozonation and ultrasonic waves. Ozonation is performed for 30 minutes, while the transesterification reaction is aided by ultrasonic wave frequency variation 28 and $35 \mathrm{kHz}$ respectively for 30 minutes. The results showed that the use of ultrasonic waves with frequency of $35 \mathrm{kHz}$ in the transesterification reaction to the ozonized Calophyllum inophyllum oil from esterification reaction produced biodiesel relatively accordance with the standards of biodiesel Indonesia. Biodiesel produced in these conditions have the acid value of $0.70 \mathrm{mgKOH} / \mathrm{g}$ biodiesel, iodine number 50.34 $\mathrm{g} \mathrm{I}_{2} / 100 \mathrm{~g}$, the flash point of $122.4^{\circ} \mathrm{C}$, cetana numbers of 102.5 , density of $0.9088 \mathrm{~g} / \mathrm{cm}^{3}$, and a viscosity of 9.5 cSt. Biodiesel yield that obtained from the best synthesis condition is $77.0 \%$.
\end{abstract}

Keywords: biodiesel, Calophyllum inophyllum oil, ozonation, transesterification, ultrasonic.

\section{Pendahuluan}

BPPT menyatakan bahwa konsumsi energi final di Indonesia pada periode 2000-2012 meningkat rata-rata sekitar $2,9 \%$ per tahun dengan konsumsi energi dominan berupa bahan bakar minyak seperti bensin, minyak diesel, minyak tanah, dan minyak bakar [1]. Lambat laun ketersediaan sumber energi ini akan terus menipis sehingga dibutuhkan suatu sumber energi terbarukan yang ketersediaannya dapat terus dipasok dan bersifat ramah lingkungan, misalnya biodiesel. Jenis tanaman yang dapat digunakan sebagai bahan baku biodiesel antara lain minyak 
sawit (palm oil), minyak kelapa (coconut oil), minyak jarak pagar (Jatropha curcas oil), minyak biji kapok randu (Ceiba pantandra oil), dan masih banyak tumbuhan lainnya yang potensial untuk dijadikan sumber energy [2], salah satunya adalah minyak nyamplung. Minyak nyamplung dapat diperoleh dari biji nyamplung dengan yield relatif tinggi yaitu sekitar $40-73 \%$ dan tidak berkompetisi dengan minyak pangan. Selain itu tanaman nyamplung sudah banyak tersebar di Indonesia [3]. Produksi biji nyamplung per tahun mencapai 20 ton/ha. Biji nyamplung mempunyai kandungan minyak tinggi yaitu sekitar 40-73\%. Satu pohon nyamplung dapat menghasilkan $100 \mathrm{~kg}$ buah/tahun. Jika jarak tanam $3 \times 3,5 \mathrm{~m}^{2}$ setiap pohon menghasilkan $30 \mathrm{~kg}$ biji atau 5,1 kg minyak maka dalam 1 hektar diprediksi menghasilkan $26.973 \mathrm{~kg}$ biji atau $4.585 \mathrm{~kg}$ minyak biji nyamplung [4]. Sedangkan jenis dan komposisi asam lemak yang terdapat di dalam minyak nyamplung ditampilkan pada Tabel 1. [5]

Tabel 1. Komposisi asam lemak minyak nyamplung

\begin{tabular}{ll}
\hline \multicolumn{1}{c}{ Asam Lemak } & Komposisi, \% \\
\hline Asam Palmitoleat (C16:1) & $0,5-1$ \\
Asam Palmitat (C16:0) & $15-17$ \\
Asam Oleat (C18:1 ) & $30-50$ \\
Asam Linoleat (C18:2) & $24-40$ \\
Asam Stearat (C18:0) & $8-16$ \\
Asam Arachidat (C20:0) & $0,5-1$ \\
Asam Gadoleat (C19:1) & $0,5-1$ \\
\hline
\end{tabular}

Secara konvensional, biodiesel diproduksi melalui reaksi transesterifikasi dengan katalis basa homogen, seperti $\mathrm{NaOH}$ atau $\mathrm{KOH}$ pada suhu $65^{\circ} \mathrm{C}$ selama sekitar 60 menit [2]. Waktu reaksi sintesis biodiesel tersebut dapat direduksi dengan memperpendek molekul minyak bahan baku dan mengefektifkan pengontakan antar reaktan. Molekul minyak dapat diperpendek dengan ozonisasi. Penggunaan gelombang ultrasonik pada pembuatan biodiesel dapat mempersingkat waktu dari 1 - 6 jam menjadi kurang dari 30 - 60 menit, dan mempersingkat waktu pemisahan yang sebelumnya 5 - 8 jam menjadi kurang dari 60 menit [6]. Penelitian ini bertujuan untuk menghasilkan biodiesel dari minyak nyamplung yang telah diozonisasi melalui reaksi esterifikasi dan transesterifikasi dengan bantuan gelombang ultrasonik pada frekuensi dan lama reaksi yang divariasikan

\section{Metode Penelitian}

Degumming: Sebanyak 1 L minyak nyamplung (diperoleh dari Cilacap, Jawa Tengah) dipanaskan pada suhu $70^{\circ} \mathrm{C}$ dan diaduk selama 15 menit, kemudian ditambahkan 1\% larutan asam fosfat $85 \%$ dan diaduk selama 5 menit. Selanjutnya akuades sebanyak 20\% dari berat minyak ditambahkan dan diaduk selama 5 menit. Campuran hasil degumming didinginkan sampai suhu ruang. Campuran disentrifugasi pada kecepatan 3500 rpm selama 25 menit, lalu disaring untuk memisahkan gum dari minyak.

Ozonisasi minyak nyamplung: Minyak nyamplung hasil degumming dimasukkan ke dalam tangki oksidasi yang dilengkapi pengaduk. Saluran pengaliran ozon dihubungkan dari ozone generator merk Ozone model S2Q-OZ/2 (Canada) ke bagian lapisan bawah minyak nyamplung. Oksidasi terhadap minyak dilakukan dengan mengoperasikan ozone generator yang mampu mengubah oksigen dalam udara menjadi ozon dengan kapasitas laju alir 7,56 L/menit. Oksidasi dilakukan selama 30 menit dibantu dengan pengadukan.

Esterifikasi minyak nyamplung: Minyak nyamplung hasil oksidasi dimasukkan ke dalam reaktor esterifikasi. Kemudian ditambahkan metanol dengan rasio mol minyak terhadap metanol sebesar 1:12. Untuk mengkatalisasi reaksi digunakan larutan asam sulfat pekat sebanyak $2 \%$. Esterifikasi diselenggarakan selama 30 menit, dibantu gelombang ultrasonik dengan frekuensi divariasikan sebesar $28 \mathrm{kHz}$ dan $35 \mathrm{kHz}$. Setelah esterifikasi, biodiesel dan minyak dipisahkan dari katalisnya dengan pencucian menggunakan akuades. Sedangkan metanol sisa dipisahkan dengan distilasi.

Transesterifikasi minyak nyamplung: Minyak nyamplung yang belum terkonversi menjadi biodiesel pada tahap esterifikasi selanjutnya ditransesterifikasi dengan metanol pada rasio mol minyak terhadap metanol sebesar 1:12. Sebagai katalis digunakan $\mathrm{NaOH}$ p.a. sebanyak $2 \%$. Transesterifikasi dibantu gelombang ultrasonik dengan frekuensi sebesar $28 \mathrm{kHz}$ dan $35 \mathrm{kHz}$ selama 30 menit sambil diaduk. Hasil transesterifikasi berupa 2 lapisan. Lapisan atas adalah biodiesel kotor, sedangkan lapisan bawah adalah gliserol. Gliserol dipisahkan dengan pengendapan dalam corong pisah. Metanol sisa 
dipisahkan dengan distilasi. Untuk memisahkan $\mathrm{NaOH}$, biodiesel dicuci dengan akuades. Biodiesel selanjutnya dimurnikan dari air tersisa dengan pemanasan pada suhu $105^{\circ} \mathrm{C}$ selama 2 jam.

Analisis kualitas dan komposisi minyak dan biodiesel: Analisis sifat-sifat kimia fisik dan komposisi dilakukan terhadap minyak nyamplung sebelum dan setelah ozonisasi, setelah esterifikasi, dan biodiesel murni hasil transesterifikasi. Sifat kimia fisik dan kimia yang dianalisis adalah densitas, viskositas, bilangan asam, bilangan iodium, bilangan penyabunan, titik nyala, bilangan cetana, dan komposisi kimia. Densitas dari minyak nyamplung dan biodiesel diukur dengan prinsip gravimetri menggunakan piknometer, sedangkan bilangan asam, penyabunan, dan iodium ditentukan dengan metode analisis volumetri atau titrimetri [6]. Viskositas diukur dengan viskometer Brookfield tipe Dial Reading Viscometer model LVT (Brookfield AMETEK). Titik nyala (flash point) biodiesel ditentukan dengan alat PenskyMartens closed cup flash point tester model K16225 (Koehler Instrument Co, Inc.). Komposisi kimia dari minyak nyamplung dan biodiesel dianalisis dengan GC/MS Shimadzu Co. [8].

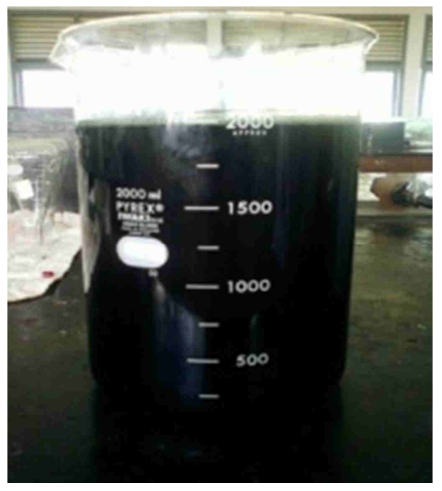

(a)

\section{Hasil dan Pembahasan}

Pada penelitian ini, hasil-hasil penelitian dalam bentuk penampilan fisik maupun hasil analisis kimia diinspeksi pada tahap-tahap proses utama, yaitu: degumming, ozonisasi, esterifikasi, dan transesterifikasi.

\section{Degumming minyak nyamplung}

Proses degumming terhadap minyak nyamplung dimaksudkan untuk meminimalkan kandungan gum/getah berupa senyawa fosfolipid dan fosfatida dalam minyak nyamplung. Perbandingan penampilan fisik antara minyak nyamplung sebelum dan setelah degumming ditampilkan pada Gambar 1. Sedangkan hasil analisis sifat fisika dan komposisi kimianya ditampilkan pada Tabel 1 dan Tabel 2.

Pada Gambar 1 nampak bahwa setelah proses degumming penampilan minyak nyamplung yang semula hijau tua pekat menjadi kuning-coklat cerah. Semakin cerahnya penampilan warna minyak nyamplung mengindikasikan bahwa sebagian besar bahan-bahan seperti gum dan khlorofil dalam minyak nyamplung telah berhasil dipisahkan.

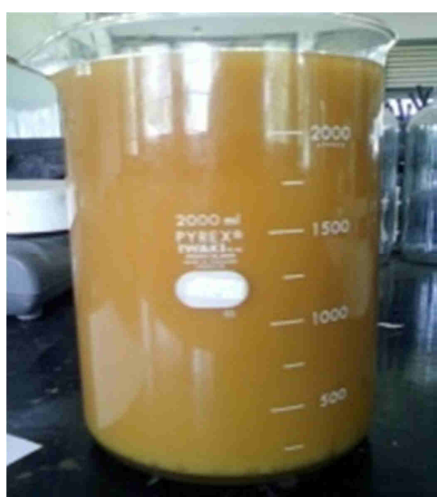

(b)

Gambar 1. Minyak nyamplung sebelum (a) dan setelah (b) degumming

Tabel 1. Hasil Analisis Minyak Nyamplung setelah Degumming

\begin{tabular}{lll}
\hline \multicolumn{1}{c}{ Parameter } & Satuan & Nilai \\
\hline Bilangan asam & $\mathrm{mg} \mathrm{KOH} / \mathrm{g}$ & 47,44 \\
Bilangan penyabunan & $\mathrm{mg} \mathrm{KOH} / \mathrm{g}$ & 139,08 \\
Bilangan iodium & $\mathrm{g} \mathrm{I}_{2} / 100 \mathrm{~g}$ & 51,33 \\
Densitas & $\mathrm{g} / \mathrm{cm}^{3}$ & 0,943 \\
Viskositas & $\mathrm{cSt}$ & 56,0 \\
Titik nyala & ${ }^{\circ} \mathrm{C}$ & 199,6 \\
\hline
\end{tabular}


Tabel 2. Jenis dan Komposisi Asam Lemak Minyak Nyamplung (hasil analisis dengan GC/MS)

\begin{tabular}{lll}
\hline Jenis Asam Lemak & Rumus Ikatan & Kadar (\%) \\
\hline Asam palmitat & C16:0 & 0,38 \\
Asam stearat & C18:0 & 15,67 \\
Asam oleat & C18:1 & 40,41 \\
Asam arachidat & C20:0 & 27,38 \\
Asam eicosenoat & C20:1 & 0,19 \\
Asam Heneicosanoat & C21:0 & 0,21 \\
Asam benehat & C22:0 & 0,23 \\
\hline
\end{tabular}

Tabel 3. Hasil Analisis Minyak Nyamplung setelah Tahap Ozonisasi

\begin{tabular}{lll}
\hline Parameter & Satuan & Nilai \\
\hline Bilangan asam & $\mathrm{mg} \mathrm{KOH} / \mathrm{g}$ & 50,24 \\
Bilangan penyabunan & $\mathrm{mg} \mathrm{KOH} / \mathrm{g}$ & 143,74 \\
Bilangan iodium & $\mathrm{g} \mathrm{I}_{2} / 100 \mathrm{~g}$ & 50,34 \\
\hline
\end{tabular}

Tabel 1 menunjukkan bahwa minyak nyamplung memiliki kandungan asam lemak bebas yang tinggi (lebih dari $2 \%$-b atau $4,0 \mathrm{mg} \mathrm{KOH} / \mathrm{g}$ ). Viskositas yang tinggi dan bilangan iodium yang rendah menunjukkan bahwa minyak nyamplung didominasi oleh asam lemak jenuh rantai panjang. Hal tersebut dipertegas oleh hasil analisis jenis dan komposisi asam lemak seperti ditampilkan pada Tabel 2.

\section{Ozonisasi dan esterifikasi}

Tahap ozonisasi dilakukan dengan maksud untuk lebih memperpendek ikatan karbon dari molekul minyak nyamplung melalui pemotongan ikatan rangkap [9]. Pada penelitian ini, keberhasilan ozonisasi didasarkan pada indikator naiknya bilangan asam dan penyabunan, serta turunnya bilangan iodium. Tabel 3 menampilkan hasil analisis minyak nyamplung setelah ozonisasi.

Perbandingan data pada Tabel 1 dan 3 menunjukkan, setelah ozonisasi, bilangan asam minyak nyamplung meningkat dari 47,44 menjadi $50,24 \mathrm{mg} \mathrm{KOH} / \mathrm{g}$ minyak. Peningkatan bilangan asam tersebut timbul sebagai akibat terputusnya beberapa ikatan rangkap pada struktur molekul trigliserida minyak nyamplung menjadi asam lemak-asam lemak bebasnya, sehingga diperlukan lebih banyak $\mathrm{KOH}$ untuk menetralkan asam lemakasam lemak tersebut [6]. Terputusnya ikatan rangkap pada minyak, juga berdampak pada turunnya ikatan tak jenuh yang ditunjukkan dengan menurunnya bilangan iodium menjadi $50,34 \mathrm{~g}$
$\mathrm{I}_{2} / 100 \mathrm{~g}$ dari semula $51,33 \mathrm{~g} \mathrm{I}_{2} / 100$ g. Tahap esterifikasi dilakukan untuk mengkonversi asam lemak bebas dalam minyak menjadi metil ester sehingga tidak mengganggu pada tahap transesterifikasi [10]. Langkah ini dilakukan karena pada tahap transesterifikasi digunakan $\mathrm{NaOH}$ sebagai katalis yang merupakan katalis basa homogen. Tahap esterifikasi yang dilakukan berhasil mengkonversi asam lemak bebas dari minyak nyamplung. Hal tersebut ditunjukkan penurunan bilangan asam dari 50,24 menjadi 8,43 dan $8,11 \mathrm{mg} \mathrm{KOH} / \mathrm{g}$ masing-masing ketika digunakan gelombang ultrasonik berfrekuensi 28 dan $35 \mathrm{kHz}$.

\section{Transesterifikasi dengan Ultrasonik}

Transesterifikasi dilakukan selama 30 menit pada suhu $65^{\circ} \mathrm{C}$ dengan rasio mol minyak/metanol sebesar 1:12 dan katalis $\mathrm{NaOH}$ sebanyak $2 \%$. Selama transesterifikasi dibantu dengan gelombang ultrasonik pada frekuensi divariasikan sebesar 28 dan $35 \mathrm{kHz}$. Hasil analisis mutu terhadap biodiesel yang dihasilkan dengan 2 variasi frekuensi gelombang ultrasonik tersebut ditampilkan pada Gambar 2. Sedangkan hasil analisis komposisi kimia ditunjukkan pada Tabel 4. Gambar 2 menunjukkan bahwa penggunaan frekuensi gelombang ultrasonik dengan frekuensi lebih tinggi pada reaksi tranesterifikasi, dihasilkan biodiesel dengan mutu lebih baik, yaitu terjadinya penurunan bilangan asam, densitas, dan viskositas 


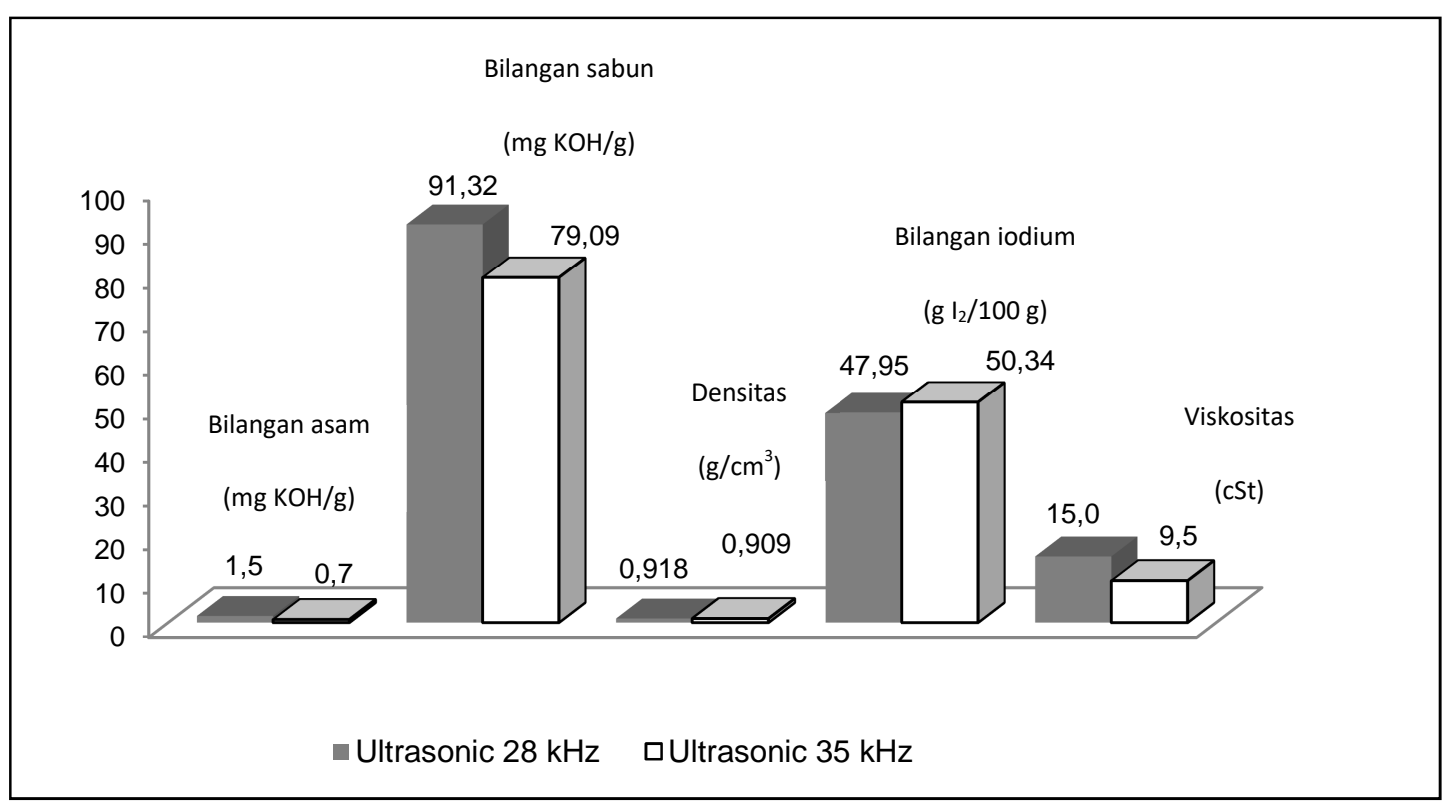

Gambar 2. Perbandingan hasil analisis mutu biodiesel pada frekuensi ultrasonik 28 dan $35 \mathrm{kHz}$

Tabel 4. Komposisi Metil Ester dari Biodiesel (transesterifikasi pada frekuensi ultrasonik $35 \mathrm{kHz}$ )

\begin{tabular}{lcc} 
Jenis metil ester & $\begin{array}{c}\text { Rumus } \\
\text { ikatan }\end{array}$ & \multicolumn{1}{c}{ Kadar } \\
\hline Metil palmitat & C16:0 & 0,38 \\
Metil stearat & C18:0 & 15,64 \\
Metil oleat & C18:1 & 40,54 \\
Metil arachidat & C20:0 & 27,33 \\
Metil eicosenoat & C20:1 & 0,18 \\
Metil Heneicosanoat & C21:0 & 0,03 \\
Metil benehat & C22:0 & 0,21 \\
\hline
\end{tabular}

Hasil tersebut sesuai dengan hasil penelitian serupa dengan bahan baku minyak biji kapuk [11]. Selain parameter mutu tersebut, juga dilakukan penentuan titik nyala dan bilangan cetana terhadap biodiesel. Bilangan cetana (BC) ditentukan dengan pendekatan berdasarkan persamaan berikut [12]:

$$
\mathrm{BC}=46,3+5458 / \mathrm{BS}-0,255^{*} \mathrm{BI}
$$

dengan $\mathrm{BS}=$ bilangan sabun dan $\mathrm{BI}=$ bilangan iodium.

Hasil penentuan titik nyala dan bilangan cetana terhadap biodiesel pada kondisi terbaik masing-masing sebesar $122,4^{\circ} \mathrm{C}$ dan 102,5 . Sedangkan Tabel 4 menampilkan hasil analisis komposisi metil ester dari biodiesel. Jenis dan kadar metil ester pada biodiesel yang dihasilkan relatif bersesuaian dengan jenis dan kadar asam lemak dalam minyak nyamplung sebagai bahan baku seperti ditampilkan pada Tabel 2 .

\section{Simpulan}

Proses ozonisasi telah relatif mampu memperpendek ikatan kimia dari minyak nyamplung didasarkan pada peningkatan bilangan asam. Pada tahap transesterifikasi dibantu gelombang ultrasonik dengan frekuensi $35 \mathrm{kHz}$ menghasilkan biodiesel dengan mutu lebih baik jika dibandingkan dengan penggunaan frekuensi 28 $\mathrm{kHz}$

\section{Pustaka}

[1] BPPT, Badan Pengkajian dan Penerapan Teknologi (2014), Outlook Energi Indonesia 2014: Pengembangan Energi untuk Mendukung Program Substitusi BBM, ISBN: 978-602-1328-02-6, Jakarta. 
[2] Gerpen, V.J., Shanks, B., Pruszko, R., Clements, D., Knothe, G. (2004). Biodiesel Production Technology, National Renewable Energy Laboratory, US Department of Energy, Colorado, USA.

[3] Hadi, W.A. (2009), Pemanfaatan minyak biji nyamplung (Calophyllum inophyllum L.) sebagai bahan bakar minyak pengganti solar. Jurnal Riset Daerah. 1044, Vol VIII, No 2.

[4] Friday, J. B \& D. Okano. (2006). Species Profiles for Pacific Island Agroforestry: Calophyllum inophyllum. www.traditionaltree.org. Diakses 3 April 2017.

[5] Debaut, V. J., Jean Y. B., \& Greentech S.A.. (2005). Tamanol a Stimulan for Callagen Synthesis for Use in Anti Wringkle and Anti Stretch Mark Products Cosmetic and Toiletries Manufacture World Wide. Greentech, St. France.

[6] Bulent, A. (2008). Ultrasonic Monitoring of Glycerol Settling during Transesterification of Soybean Oil, Bioresource Technology, Vol. 100, p: 19-24.

[7] Apriantono, A., Fardiaz, N. L. P., Sedarnawati, S., \& Budiyanto (1989). Analisis Pangan. IPB. Bogor.
[8] Onishi, K., Kato, S., Kunisawa, K., Kojima, T., Murakami, S. (2004). Production of Biodiesel by Ozone Treatment, The Society of Chemical Engineers-Japan.

[9] Zahardis, J., Petrucci, G. A. (2007). The oleic acid-ozone heterogeneous reaction system: products, kinetics, secondary chemistry, and atmospheric implications of a model system, Atmos. Chem. Phys., Vol. 7, p: 1237-1274

[10] Knothe, G., Gerpen, J. V., Krahl, J. (2005). The Biodiesel Handbook, AOCS Press, Champaign-Illinois, USA.

[11] Haryono, Kusumah, H.W, Natanael, C.L. (2014), Biodiesel Synthesis from Cotton Seed Oil through Ozonization and Ultrasonication Processes use Calcium Oxide Catalyst from Eggshell, the $3^{\text {rd }}$ International Seminar on Chemistry 2014, Department of Chemistry, Universitas Padjadjaran.

[12] Azam, M.M., Waris, A., Nahar, N.M. (2005). Prospects and Potential of Fatty Acid Methyl Esters of Some Non-traditional Seed Oils for Use as Biodiesel in India, J. Biomass \& Bioenergy Vol.29, p: 293-302. 